\title{
Use of Cognitive Smart Robots with Technological Thinking and Behavior in Social Sphere
}

\section{Evgeniy Bryndin*}

Department of Scientific, Research center "Estestvoinformatika", Russia

*Corresponding author: Evgeniy Bryndin, scientific department, Research center "Estestvoinformatika”, Novosibirsk, Russia.

\section{Abstract}

Now in the world in many spheres of activity Russian, European, Japanese, Chinese, American smart robots are used. Development of technologies conducts to the fact that new robots appear. Create robots and train them for work in the social sphere. Robots can find environmental pollution, fire-dangerous situations and successfully prevent them. A few years ago there were also mobile robots able to be guided in space.

Keywords: Imitative thinking and behavior; Cognitive professional robot

Robot with Technological Thinking and Behavior on Service of Society

Robots become independent subjects of social environment [1-7]:

1. Robot of the informant and the smart guide for mass actions, in the smart cities, in the conditions of space and big shops (Figure 1).

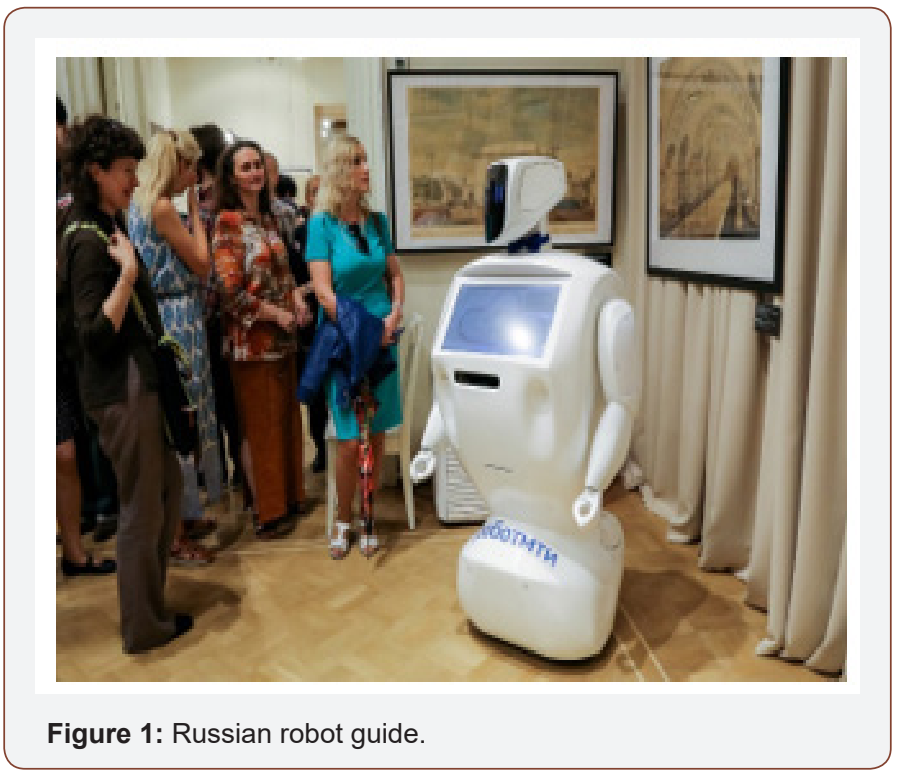

2. Smart robotic café and drugstores (Figure 2).

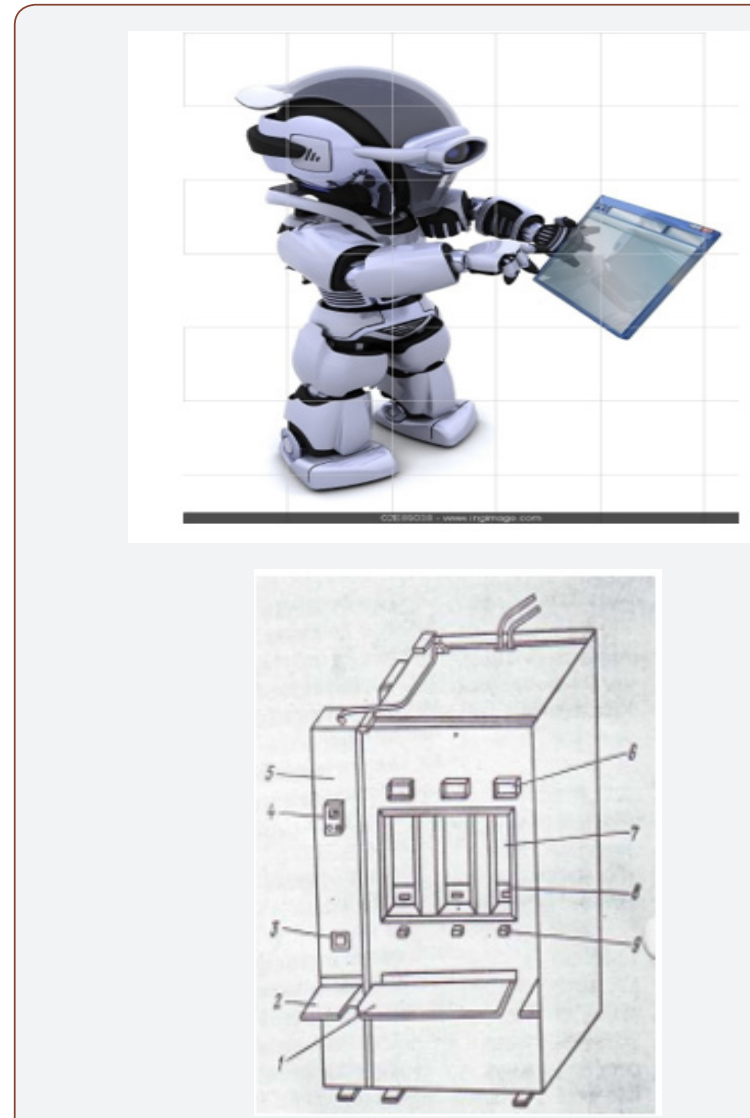

Figure 2: European cognitive professional robot-seller of café 
3. Consultant, lecturer and teacher (Figure 3).

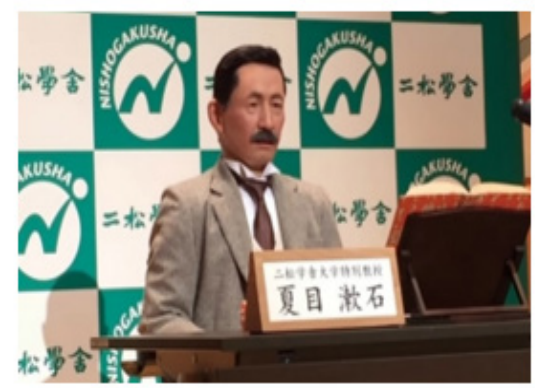

Figure 3: Japanese robot lecturer.

4. Nurse in hospitals (Figure 4).

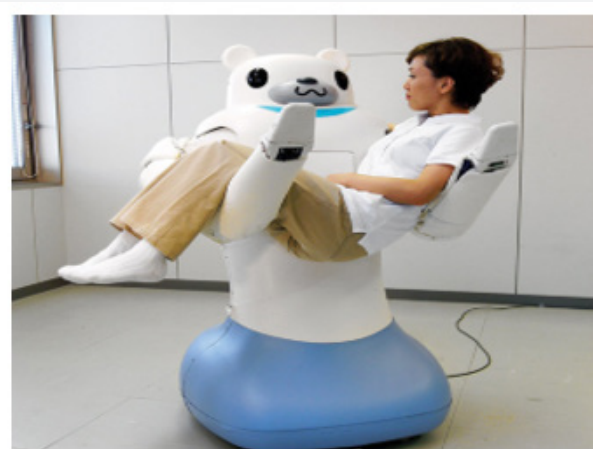

Figure 4: Japanese robot nurse.

5. Smart robot vacuum cleaner (Figure 5).

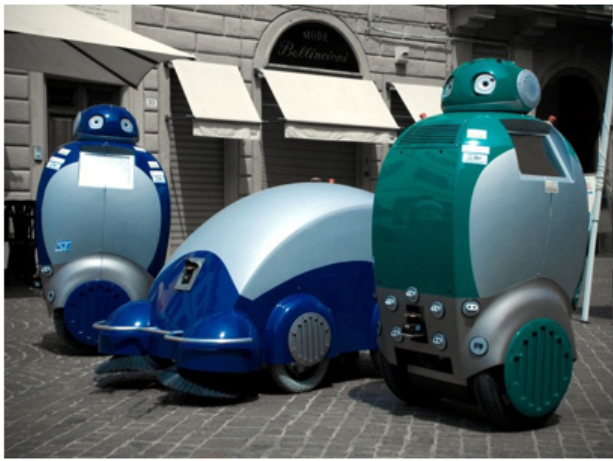

Figure 5: European smart robot vacuum cleaner.

6. Robot-Android volunteer ASIMO (Figure 6).

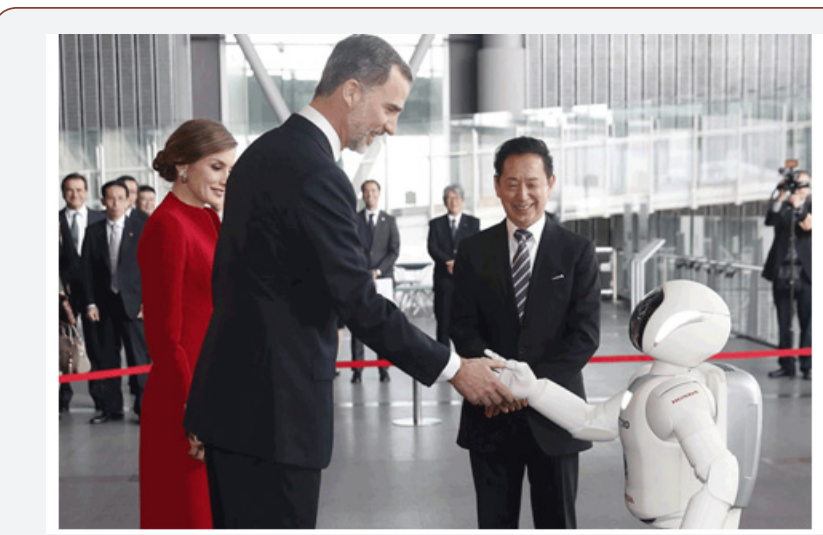

Figure 6: Japanese robot-Android volunteer ASIMO.
7. Mobile robot security guard Atlas (Figure 7).

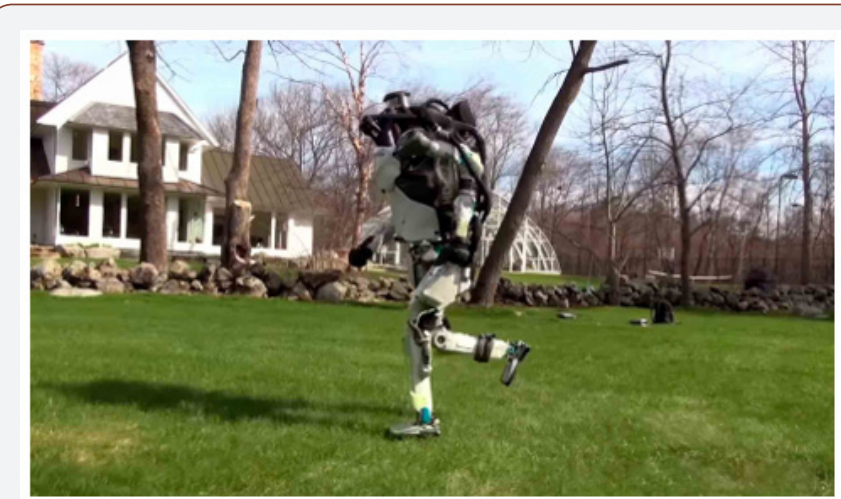

Figure 7: American mobile robot security guard Atlas.

8. Chinese humanoid robot (Figure 8).

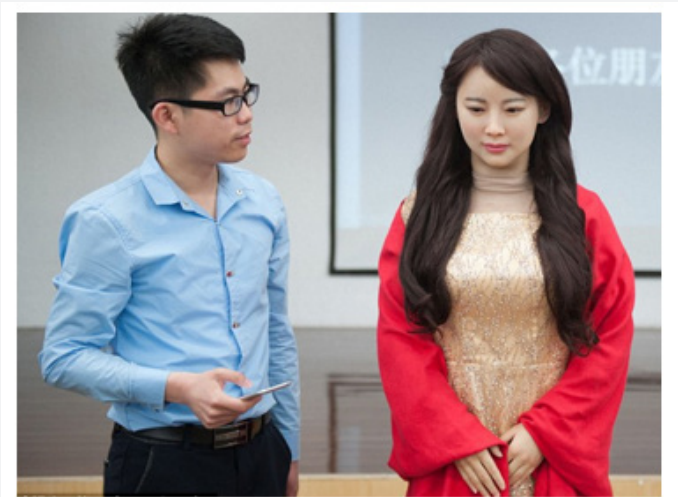

Figure 8: Chinese humanoid robot (Jia Jia).

\section{Conclusion}

The cognitive robots with communicative and associative logic of thinking having the systems of machine retraining of realization of information requirements will be able quickly to change professional qualification and competences. The international scientific and engineering society gradually moves to technical realization of the cognitive professional robot with retraining. In the future in labor market cognitive robots with retraining will perform professional works, and the person will occupy a niche of scientific research of creative innovative activity.

\section{Acknowledgment}

None.

\section{Conflicts of Interest}

No conflicts of interest

\section{References}

1. Evgeniy Bryndin (2015) Robot with imitative thinking. PNIPU bulletin: Electrical equipment, Information technologies, Control systems", N. 14. PNIPU, pp. 5-36.

2. Bryndin EG (2016) Cognitive robots. Inter. Conf. "Management of development of large-scale systems (MLSD’2016). M.: IPM RAS, pp. 285294.

3. Evgeniy Bryndin (2017) Cognitive Robots with Imitative Thinking for Digital Libraries, Banks, Universities and Smart Factories. International Journal of Management and Fuzzy Systems 3(5): 57- 66. 
4. Evgeniy Bryndin (2017) Program Hierarchical Realization of Adaptation Behavior of the Cognitive Mobile Robot with Imitative Thinking. International Journal of Engineering Management 1(4): 74-79.

5. Evgeniy Bryndin (2018) Technological Thinking, Communication and Behavior of Androids. Communications 6(1): 13-19.
6. Evgeniy Bryndin (2018) Communicative Associative Logic of Cognitive Professional Robot with Imitative Thinking. Journal Engineering Mathematics 2(2): 79-85.

7. Evgeniy Bryndin (2018) Directions of Development of Industry 4.0, Digital Technology and Social Economy. American Journal of Information Science and Technology 2(1): 9-17. 